\title{
Adolescent growth and pubertal progression in the Silver-Russell syndrome
}

\author{
P S W DAVIES, ${ }^{*}$ R VALLEY, $\dagger$ AND M A PREECE* \\ ${ }^{*}$ Department of Growth and Development, Institute of Child Health, London, and †Department of \\ Anaesthesia, Hospital for Sick Children, Toronto, Canada
}

SUMMARY The pattern of growth and development of 18 adolescent children with the Silver-Russell syndrome was studied. Mature height was about -3.6 standard deviation scores in both sexes. This is comparable to the height reduction at diagnosis, which has been reported previously. The pattern of puberty and adolescent growth was essentially normal and occurred at a marginally earlier time than normal, although in this small series the differences were not significant. In the girls there was a tendency to gain subcutaneous fat after puberty. This trend was not apparent in the boys.

Of the recognisable growth disorders presented to the paediatrician one of the more common is the Silver-Russell syndrome. The characteristic physical features of this syndrome were described independently but almost simultaneously. ${ }^{12}$ Such patients are usually thin, with short stature noticeable from birth. There are a number of dysmorphic features such as a small and triangular face, lowset ears, and clinodactyly.

The work of Tanner et al, ${ }^{3}$ described in detail the natural history of growth in this disorder. As these authors stated, however, few of their patients had reached maturity and thus a quantitative description of the later stages of longitudinal growth was not possible. Since that time a number of the patients have reached physical maturity, and sufficient auxological data have been collected to allow a longitudinal analysis of physical growth in this syndrome.

\section{Methods}

The criteria adopted by Tanner et $a l^{3}$ for the diagnosis of Silver-Russell syndrome were: (a) stature that was two standard deviations below the 50th centile for height on British standards; (b) birth weight when adjusted for sex, length of gestation, birth order, and maternal height two standard deviations or more below the 50th centile on the Tanner-Thomson standards ${ }^{4}$; and (c) absence of any other recognisable syndrome, and of chromosomal, endocrine, metabolic, chondrodysplastic, or psychiatric disturbances that would account for the short stature.
The clinical records and existing growth data of the patients who had satisfied those criteria were $\vec{\bullet}$ reviewed. The original diagnosis of Silver-Russell $\infty$ syndrome was reassessed. In addition to the criteria adopted by Tanner $e t a l,{ }^{3}$ patients had to exhibit the classical features of this syndrome-for example, clinodactyly, a triangular face, and lowset ears. Patients to be included in this study were then selected by virtue of firstly, having stopped growing in the sense that they had grown less than $1 \mathrm{~cm}$ in the last year of measurement and secondly, that their growth had been measured for at least three years before the onset of puberty. These selection criteria yielded a total of 18 patients, nine of each sex.

Using the longitudinal growth data produced from these patients it was possible to describe the mean growth curve of a number of linear dimensions such as height and sitting height. The growth curves of such dimensions have a characteristic and similar shape in normal individuals. When attempting to describe the 'typical' or 'mean' growth curve of a specific group of individuals, however, account must be taken of the variability in timing, duration, and $N$ intensity of biological events; in particular the $N$ adolescent growth spurt. If this variation in the tempo of growth is not accommodated the growth $\omega$ curve found by simply taking the mean of individuals' measurements at different ages will not be representative of the true mean curve. In such a $\stackrel{\oplus}{\oplus}$ growth curve the duration of the adolescent growth spurt is lengthened and its intensity reduced.

In the study reported here, as we wished to study specifically the growth period around puberty, special attention was paid to this phase-effect. In the 
past this problem has been overcome by centering individual growth curves on discernable common events notably the age at peak height velocity (PHV). An alternative approach is to apply a mathematical model to the individual growth curves and use the mean values of the mathematical parameters that describe the individual curves to produce a mean constant curve. ${ }^{6}$

The growth curve for many anthropometric variables can be defined by the model described by Preece and Baines that used five parameters, each being associated with meaningful biological events. ${ }^{7}$ This mathematical model is:

$$
\mathrm{h}=\mathrm{h}_{1}-\frac{2\left(\mathrm{~h}_{1}-\mathrm{h}_{\theta}\right)}{\exp \left[\mathrm{s}_{0}(\mathrm{t}-\theta)\right]+\exp \left[\mathrm{s}_{1}(\mathrm{t}-\theta)\right]}
$$

where $h$ is height at age $t, h_{1}$ is final or adult height, $s_{0}$ and $s_{1}$ are rate constants, $\theta$ is a time constant, and $\mathrm{h}_{\theta}$ is height at age $=\theta$. It is an improvement on previous models that only considered parts of the growth curve $^{89}$ or produced many, sometimes biologically meaningless, parameters. ${ }^{10}$ This method of growth modelling was applied to the longitudinal data of each child for stature, sitting height, and subischial leg length.

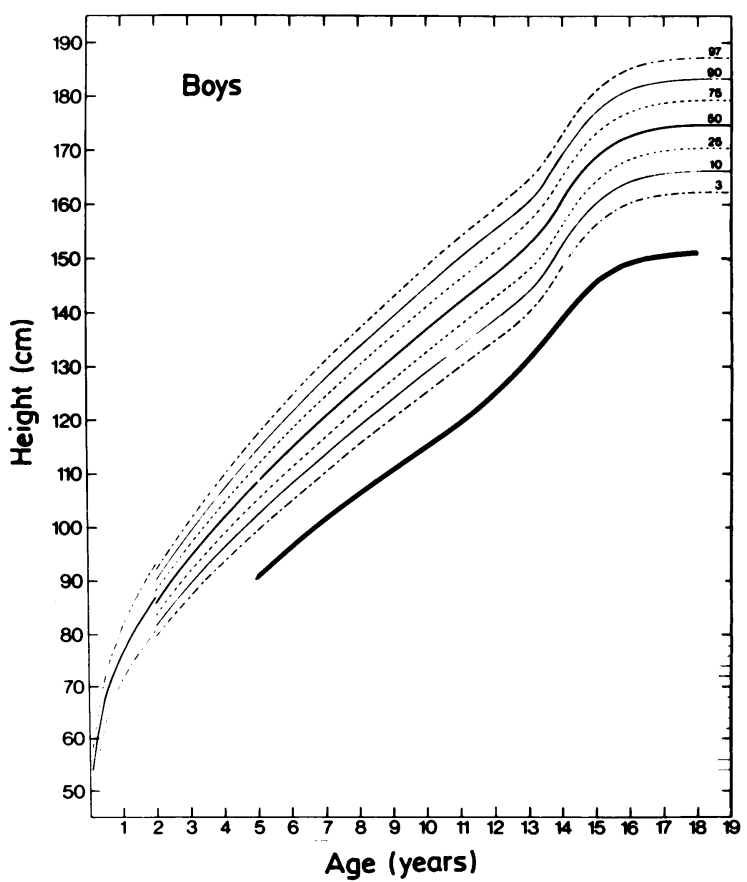

Table 1 Biological parameters derived from the

Preece-Baines curves pertaining to stature

\begin{tabular}{lcr}
\hline & $\begin{array}{l}\text { Boys } \\
\text { Mean }(S D)\end{array}$ & \multicolumn{1}{l}{$\begin{array}{l}\text { Girls } \\
\text { Mean }(S D)\end{array}$} \\
\hline $\begin{array}{l}\text { Adult height }(\mathrm{cm}) \\
\begin{array}{l}\text { Size at peak height } \\
\text { velocity (cm) }\end{array}\end{array}$ & $150 \cdot 7(2 \cdot 8)$ & $142 \cdot 0(6 \cdot 2)$ \\
$\begin{array}{l}\text { Age at peak height } \\
\text { velocity (years) }\end{array}$ & $135.7(3 \cdot 2)$ & $127.5(5 \cdot 5)$ \\
$\begin{array}{l}\text { Velocity at peak height } \\
\text { velocity (cm/year) }\end{array}$ & $13.6(1 \cdot 0)$ & $11.6(1.4)$ \\
\hline
\end{tabular}

A constant component of the Silver-Russell syndrome is that patients are thin, with skinfold thicknesses being appreciably below normal. By the nature of their growth curves measurements of skinfolds do not easily lend themselves to curve fitting. In order to describe the changes in these measurements that occur throughout growth, standard deviation scores (SDS) were calculated for the skinfold measurements at the tricep and subscapular sites, allowing for age and sex differences. These scores were determined by: $\mathrm{SDS}=(\mathrm{X}-\overline{\mathrm{x}}) / \mathrm{Sx}$ where at the age in question, $\mathrm{X}$ is the measurement, $\overline{\mathrm{x}}$ is the mean of the measurement, and Sx is the standard

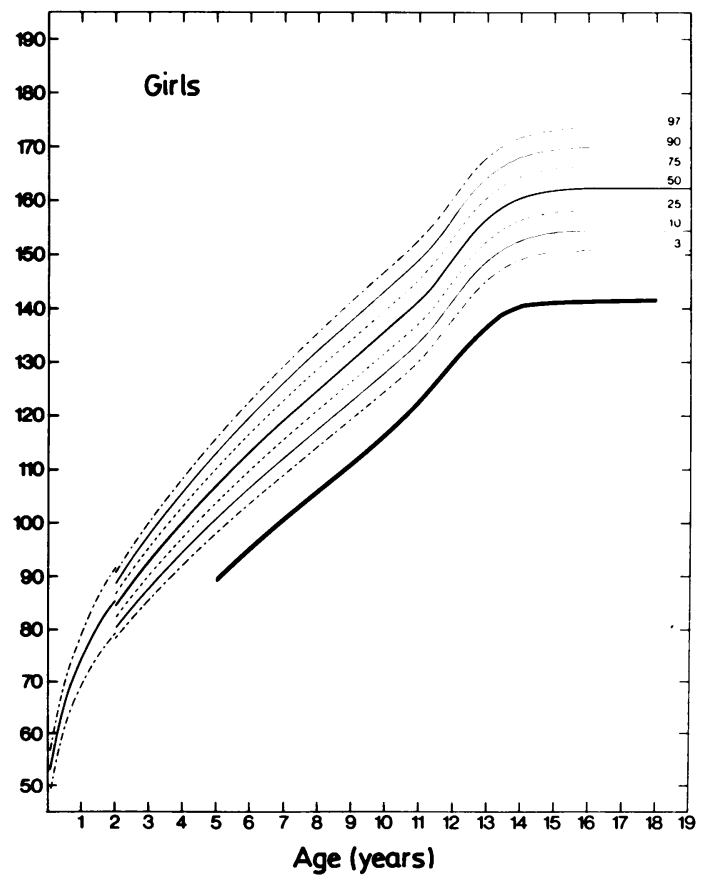

Fig 1 Mean constant curves for height attained in boys and girls plotted on British standards. 
deviation of the measurement. The standardising data were taken from the data of Tanner and Whitehouse. ${ }^{11}$ Standard deviation scores for both skinfold sites were calculated from the data existing closest to three years before the age at PHV, at age of PHV, and three years after this event.

A disturbance of pubertal events has been cited as occurring in some cases of Silver-Russell syndrome. ${ }^{1}$ To obtain some indication of the pattern of development of sexual characteristics for the children in this study the ages of attainment of puberty stages were recorded for each child. ${ }^{12}$

\section{Results}

Table 1 shows the means and standard deviations of some of the biological parameters derived from the Preece-Baines curve, which were obtained from the individual fits to the stature data of the boys and girls.

In both sexes adult height was well below the third centile for normal British children. Indeed, the standard deviation scores of adult height for boys and girls was $-3 \cdot 61$ and $-3 \cdot 58$, respectively. Fig 1 shows the mean constant curves for stature for both sexes. Fig 2 shows the height velocity curves derived from these and plotted on standards for normal British children.

Table 2 shows the derived biological parameters for sitting height and subischial leg length for both sexes. Adult sitting height was $-3 \cdot 29$ standard

Table 2 Biological parameters derived from the Preece-Baines curves pertaining to sitting height and subischial leg length

\begin{tabular}{|c|c|c|}
\hline & $\begin{array}{l}\text { Boys } \\
\text { Mean (SD) }\end{array}$ & $\begin{array}{l}\text { Girls } \\
\text { Mean (SD) }\end{array}$ \\
\hline & \multicolumn{2}{|c|}{ Sitting height } \\
\hline Adult sitting height $(\mathrm{cm})$ & $82 \cdot 7(1 \cdot 6)$ & $78 \cdot 2(3 \cdot 0)$ \\
\hline \multicolumn{2}{|l|}{ Size at peak sitting height } & $70 \cdot 9(2 \cdot 8)$ \\
\hline $\begin{array}{l}\text { Age at peak sitting height } \\
\text { velocity (years) }\end{array}$ & $14 \cdot 0(1 \cdot 0)$ & $12 \cdot 2(1 \cdot 6)$ \\
\hline \multirow[t]{2}{*}{$\begin{array}{l}\text { Velocity at peak sitting } \\
\text { height velocity ( } \mathrm{cm} / \text { year })\end{array}$} & $5 \cdot 1(1 \cdot 0)$ & $3 \cdot 9(0 \cdot 9)$ \\
\hline & \multicolumn{2}{|c|}{ Subischial leg length } \\
\hline Adult subischial length $(\mathrm{cm})$ & $68 \cdot 4(2 \cdot 2)$ & $64 \cdot 2(4 \cdot 5)$ \\
\hline $\begin{array}{l}\text { Size at peak leg length } \\
\text { velocity }(\mathrm{cm})\end{array}$ & $61.4(2 \cdot 0)$ & $57 \cdot 3(3 \cdot 7)$ \\
\hline $\begin{array}{l}\text { Age at peak leg length } \\
\text { velocity (years) }\end{array}$ & $13 \cdot 0(0 \cdot 9)$ & $11 \cdot 0(1 \cdot 1)$ \\
\hline $\begin{array}{l}\text { Velocity at peak leg length } \\
\text { velocity }(\mathrm{cm} / \text { year })\end{array}$ & $4 \cdot 7(1 \cdot 3)$ & $4 \cdot 3(0 \cdot 6)$ \\
\hline
\end{tabular}

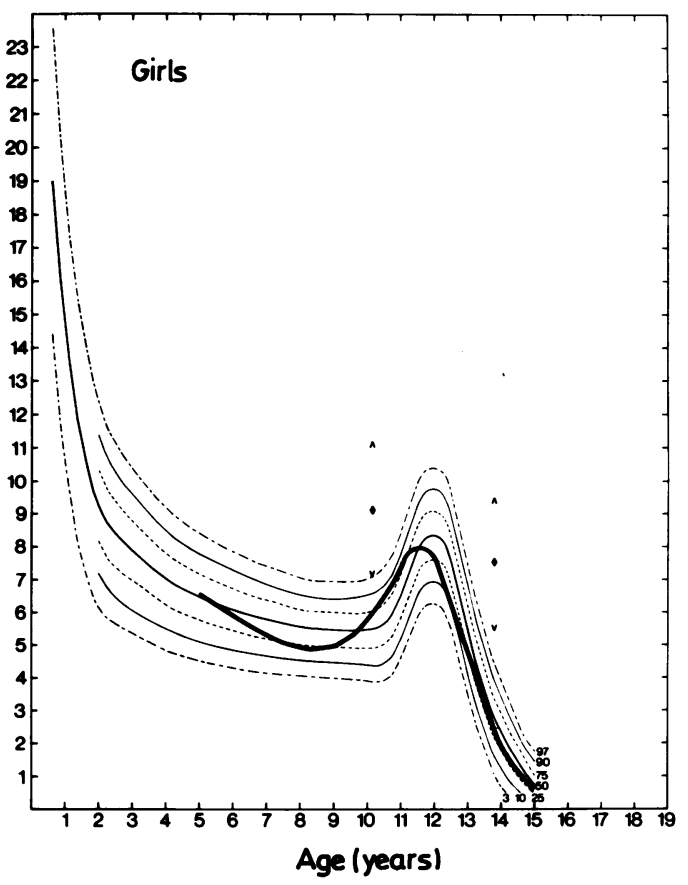

Fig 2 Mean constant curves for height velocity in boys and girls plotted on British standards.

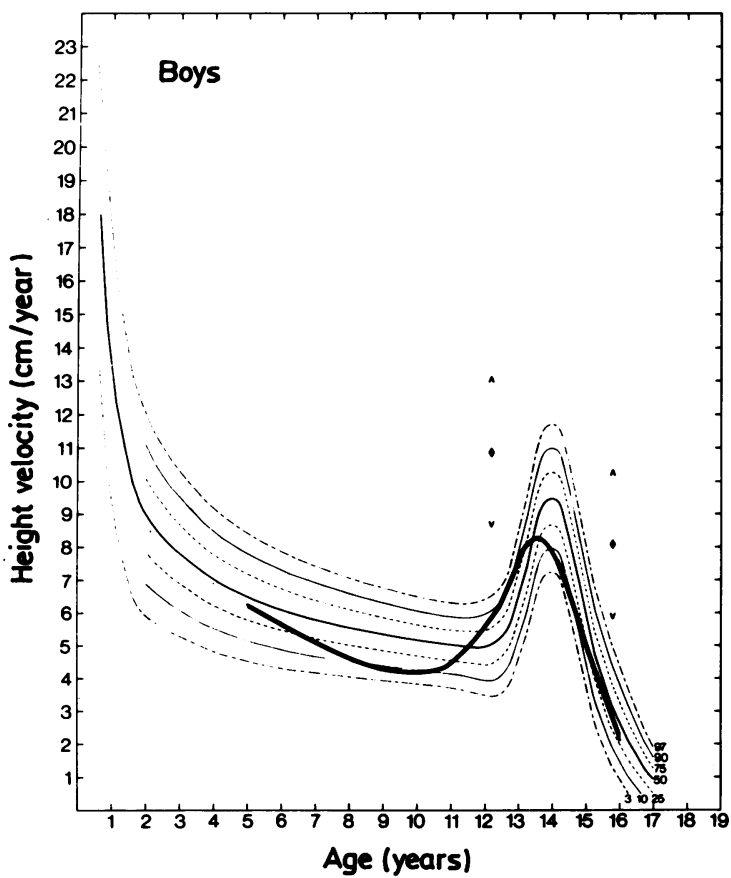


deviation scores below the mean in the boys and -3.08 for the girls. Adult subischial leg length was -3.06 standard deviation scores below the mean in the boys and $-2 \cdot 64$ below the mean in the girls.

The mean values of the standard deviation scores at the triceps and subscapular skinfold sites in both sexes are shown in table 3 . In all but one case the mean skinfold standard deviation score is below the average for normal British children.

Mean age of attainment for each stage of pubertal development and mean age of menarche are shown in table 4. The centile position of these ages as compared with normal British children is shown in the third column. As would be expected the girls show pubertal changes at a slightly earlier age than the boys.

Table 3 Mean standard deviation scores of two skinfolds (SEM)

\begin{tabular}{|c|c|c|}
\hline & Triceps & Subscapular \\
\hline \multirow{5}{*}{$\begin{array}{l}3 \text { years before peak } \\
\text { height velocity } \\
\text { At peak height velocity } \\
3 \text { years after peak } \\
\text { height velocity }\end{array}$} & \multicolumn{2}{|c|}{ Boys } \\
\hline & & \\
\hline & $-0 \cdot 13(0 \cdot 17)$ & $-0.03(0.18)$ \\
\hline & $-0.23(0 \cdot 24)$ & $-0.04(0.17)$ \\
\hline & $-0 \cdot 11(0 \cdot 25)$ & $-0.09(0.20)$ \\
\hline \multirow{4}{*}{$\begin{array}{l}3 \text { years before peak } \\
\text { height velocity } \\
\text { At peak height velocity } \\
3 \text { years after peak } \\
\text { height velocity }\end{array}$} & \multicolumn{2}{|c|}{ Girls } \\
\hline & $-0.50(0 \cdot 17)$ & $-0.25(0.14)$ \\
\hline & $-0.33(0.20)$ & $-0 \cdot 15(0 \cdot 18)$ \\
\hline & $-0.13(0.31)$ & $+0.03(0.17)$ \\
\hline
\end{tabular}

Table 4 Attainment of puberty stages and age of menarche (SEM). The centile position of each age is shown in the third column. Conventionally centile positions below the 50th centile indicate delayed attainment of a puberty stage

\begin{tabular}{|c|c|c|}
\hline Stage & $\begin{array}{l}\text { Mean age of } \\
\text { attainment }\end{array}$ & $\begin{array}{l}\text { Centile } \\
\text { position }\end{array}$ \\
\hline & \multicolumn{2}{|c|}{ Boys } \\
\hline Pubic hair 2 & $12 \cdot 52(0 \cdot 35)$ & $\sim 50$ th \\
\hline Pubic hair 3 & $13 \cdot 58(0.28)$ & $\sim 50$ th \\
\hline Pubic hair 4 & $14.57(0.35)$ & $\sim 50$ th \\
\hline Genitalia 2 & $12.58(0.33)$ & 25 th-50th \\
\hline Genitalia 3 & $13.68(0.41)$ & $\sim 25$ th \\
\hline \multirow[t]{2}{*}{ Genitalia 4} & $14.88(0.45)$ & 10th-25th \\
\hline & \multicolumn{2}{|c|}{ Girls } \\
\hline Pubic hair 2 & $11 \cdot 60(0.46)$ & $\sim 50$ th \\
\hline Pubic hair 3 & $12.51(0.49)$ & $\sim 50$ th \\
\hline Pubic hair 4 & $13.04(0.60)$ & $\sim 50$ th \\
\hline Breast 2 & $11.47(0.61)$ & $\sim 50$ th \\
\hline Breast 3 & $12.61(0.50)$ & 25 th-50th \\
\hline Breast 4 & $13.22(0.66)$ & $\sim 50$ th \\
\hline Menarche & $12.98(0.59)$ & $\sim 50$ th \\
\hline
\end{tabular}

\section{Discussion}

The aim of this work was to describe some of the features of longitudinal growth in the Silver-Russell syndrome. For a number of patients sufficient auxological data have been collected to produce growth curves and to fit a mathematical model to those curves. Therefore, the mean constant curve for a number of body dimensions can be described. Standard deviation scores were calculated for tricep and subscapular skinfold measurements and the age of attainment of puberty stages were also recorded.

The major presenting feature of this syndromeshort stature-affects both sexes to the same degree. The slight difference in the adult height standard deviation scores between boys and girls is not significant $(p>0.05)$. The mean height standard deviation score at referral found by Tanner et $a l^{3}$ was $-3 \cdot 58$, remarkably similar to the reduced adult height found in this study. This indicates that there is little catch up growth in the Silver-Russell syndrome during childhood and adolescence. It may also confirm the observation of Tanner et al ${ }^{3}$ that growth essentially procedes normally in childhood; the patient, however, always remains small in comparison with his or her peers. In contrast to this it has been reported in a recent publication that five out of 15 patients diagnosed as having Silver-Russell syndrome experienced catch up growth. ${ }^{13}$ It should be noted, however, that a number of the patients described by these workers would not have satisfied the diagnostic criteria adopted in our study.

The Preece-Baines curve produces a number of biological parameters pertaining to the adolescent growth spurt. An abnormal pattern and timing of pubertal events was originally reported by Silver $e t$ $a l$ as one of the features of the syndrome. ${ }^{1}$ Age at PHV in both sexes was about six months earlier than for normal British children. Nevertheless, as the standard deviation of the timing of this event is about 0.9 of a year in both sexes, ${ }^{14}{ }^{15}$ the age at PHV found in this work is well within normal limits. The actual velocity of growth at this time, 8.3 $\mathrm{cm} /$ year in the boys and $8.0 \mathrm{~cm} /$ year in the girls, is also well within normal expectations, although slightly below the mean velocity found for British children. Other biological parameters derived from the mean constant curve such as the age at take off (the beginning of the adolescent growth spurt) and the velocity at take off are also within normal ranges, although again slightly reduced. Consequently, all these factors tend to indicate an essentially normal adolescent growth spurt that is reduced slightly in magnitude and occurs slightly early. This description of the adolescent growth spurt is supported by the height velocity curves shown in fig 2 . 
The standard deviation scores for adult sitting height and subischial leg length would suggest that leg length is reduced to a lesser degree than sitting height. This difference, however, is not significant at the $5 \%$ level and therefore we cannot conclude that adults with Silver-Russell syndrome are disproportionate. In normal British children leg length reaches its peak velocity on average about six months earlier than the trunk. Also, the spurt at adolescence in sitting height is greater than in the lower limbs. In the group of children included in this study peak leg length velocity is roughly one year in advance of peak sitting height velocity. This difference is significant at the $5 \%$ level in the boys but not in the girls. The girls have a greater peak velocity in leg length than in sitting height and although the difference between the peak velocities is not significant, this pattern is very similar to that seen in normal adolescents.

The values of the mean standard deviation scores for the triceps and subscapular skinfold measurements shown in table 3 are similar to those reported for the triceps skinfold site alone by Tanner et al. ${ }^{3}$ The mean standard deviation scores are closer to the mean for the normal population in this present group than is usually found in younger children with Silver-Russell syndrome. ${ }^{3}$ The data presented here support the description that body composition tends to normality in later childhood and adolescence. ${ }^{5}$

The mean age of attainment of puberty stages as shown in table 4 shows that for the group of children in this study the mean ages are similar to those found in normal British children, with the ages lying on or close to the 50th centile. Mean age of menarche in the nine girls studied here is remarkably close to the mean age of 13.0 years usually cited for normal British girls. Age of attainment of genitalia stages 2 to 4 in boys occur progressively later in comparison with normal British children. The 50th centile for time spent between these stages is 1.9 years in normal children, ${ }^{15}$ while in this study the time spent between the stages was 2.3 years. Nevertheless, this value is still within the normal range. Thus we must conclude that there is a normal pubertal development of sexual characteristics in this syndrome. The belief that there is a disturbance of pubertal development in Silver-Russell syndrome stems from early descriptions of the growth disorder. Since that time more information has become available regarding normal variation in timing of pubertal events and it now seems that adolescent development is essentially normal. Nevertheless, there are still contradictory reports in the literature pertaining to the normality of pubertal events. In a recent report a potential relation between intrauterine growth retardation and an early adolescence has been cited, ${ }^{16}$ while the timing of pubertal events has been reported as normal in an equally recent work. ${ }^{17}$

It has been postulated that in the Silver-Russell syndrome intrauterine growth retardation results in a reduction in total body cell mass, and that after birth growth proceeds normally with the child always remaining small in comparison with his or her peers. This study would certainly lend support to the normality of physical growth. Puberty occurs essentially normally both in terms of the adolescent growth spurt and the development of sexual characteristics.

The characteristic appearance of many patients with this syndrome aids in diagnosis, however, the prognosis with regard to adult stature is poor. Human growth hormone has been shown to have variable and short term effects on growth velocity, with some patients showing growth acceleration. ${ }^{18}$ Further trials over longer periods are now required and any long term benefit can be judged against the data reported here.

\section{References}

1 Silver HK, Kiyasu N, George J, et al. Syndrome of congenital hemihypertrophy, shortness of stature and elevated urinary gonadotrophins. Pediatrics 1953;12:368-75.

2 Russell A. A syndrome of intrauterine dwarfism recognisable at birth with craniofacial dysotosis, disproportionately short arms and other abnormalities. Proceedings of the Royal Society of Medicine 1954;47:1040-4.

3 Tanner JM, Lejarraga H, Cameron N. The natural history of the Silver-Russell syndrome: a longitudinal study of thirty-nine cases. Pediatr Res 1975;9:611-23.

4 Tanner JM, Thomson AM. Standards for birthweight at gestation periods from 32 to 42 weeks allowing for maternal height and weight. Arch Dis Child 1970;45:566-9.

5 Smith DW. Recognizable patterns of human malformation. Philadelphia: WB Saunders, 1982.

${ }^{6}$ Merrell M. The relationship of individual growth to average growth. Hum Biol 1931;3:37-70.

7 Preece MA, Baines MJ. A new family of mathematical models describing the human growth curve. Ann Hum Biol 1978;5:1-24.

$\checkmark$ Deming J. Application of the Gompertz curve to the observed pattern of growth in length of 48 individual boys and girls during the adolescent cycle of growth. Hum Biol 1957;29:83-122.

${ }^{9}$ Tanner JM, Whitehouse RH, Marubini E, Resele LF. The adolescent growth spurt of boys and girls of the Harpenden growth study. Ann Hum Biol 1976;3:109-26.

10 Stützle W, Gasser T, Largo R. Analysis of the adolescent growth spurt using smoothing spline functions. Rennes: Reunion de Coordination des Recherches sur la Croissance et le Developpement. Paris: Centre International de l'Enfance, 1976.

11 Tanner JM, Whitehouse RH. Revised standards for triceps and subscapular skinfolds in British children. Arch Dis Child 1975;50:142-5.

12 Tanner JM. Growth at adolescence. Oxford: Blackwell Scientific Publishers, 1962.

13 Saal HM, Pagan RA, Pepin MG. Re-evaluation of RussellSilver syndrome. J Pediatr 1985;107:733-7.

14 Marshall WA, Tanner JM. Variations in the pattern of pubertal changes in girls. Arch Dis Child 1969;44:291-303. 
15 Marshall WA, Tanner JM. Variations in the pattern of pubertal changes in boys. Arch Dis Child 1970:45:13-23.

16 Arisaka O, Arisaka M, Kiyokawa N, Shimizu T, Nakayama Y, Yabuta K. Intra-uterine growth retardation and early adolescent growth spurt in two sisters. Clin Pediatr (Phila) 1986:25:559-61.

17 Job JC, Rolland A. Natural history of intra-uterine growth retardation: pubertal growth and adult height. Arch Fr Pediatr 1986;43:301-6.

18 Tanner JM, Whitehouse RH, Hughes PCR, Vince FP. Effect of human growth hormone treatment for 1 to 7 years on growth of 100 children, with growth hormone deficiency, low birthweight. inherited smallness, Turner's syndrome and other complaints. Arch Dis Child 1971;46:745-82.

Correspondence to Mr PSW Davies. Dunn Nutrition Unit. Downhams Lane, Milton Road, Cambridge CB4 1XJ.

Received 9 October 1987 